\title{
Type IV Pilus of Pseudomonas aeruginosa \\ Confers Resistance to Antimicrobial Activities of the Pulmonary Surfactant Protein-A
}

\author{
Rommel Max Tan Zhizhou Kuang Yonghua Hao Gee W. Lau \\ Department of Pathobiology, University of Illinois at Urbana-Champaign, Urbana, III., USA
}

\section{Key Words}

Surfactant protein-A · Pseudomonas aeruginosa - Type IV

pilus - Opsonization - Membrane permeabilization .

Adhesins

\begin{abstract}
Pseudomonas aeruginosa $(P A)$ is a Gram-negative bacterial pathogen commonly associated with chronic lung infections. Previously, we have identified several $P A$ virulence factors that are important for resistance to the surfactant protein-A (SP-A), a pulmonary innate immunity protein that mediates bacterial opsonization and membrane permeabilization. In this study, we demonstrate that the type IV pilus (Tfp) is important in the resistance of $P A$ to the antibacterial effects of SP-A. The Tfp-deficient mutant $\triangle$ pilA is severely attenuated in an acute pneumonia model of infection in the lungs of wild-type mice, but is virulent in the lungs of SP- $\mathrm{A}^{-/-}$mice. The $\triangle$ pilA bacteria are more susceptible to SP-A-mediated aggregation and opsonization. In addition, the integrity of the outer membranes of $\triangle$ pilA bacteria is compromised, rendering them more susceptible to SP-A-mediated membrane permeabilization. By comparing Tfp extension and retraction mutants, we demonstrate that the increased susceptibility of $\triangle p i l A$ to SP-A-mediated opsonization requires the total ab-
\end{abstract}

\section{KARGER}

E-Mail karger@karger.com

www.karger.com/jin sence of Tfp from PA cells. Finally, we provide evidence of increased expression of nonpilus adhesin OprH that may serve as an SP-A ligand, resulting in increased phagocytosis and preferential pulmonary clearance of $\Delta p i l A$.

C 2013 S. Karger AG, Basel

\section{Introduction}

Pseudomonas aeruginosa (PA) is an opportunistic Gram-negative bacterial pathogen commonly associated with acute or chronic infection of mechanically damaged (ventilator-associated pneumonia), immunocompromised (HIV, malignancies and immunosuppressive drugs) and mechanically obstructed (cystic fibrosis and chronic obstructive pulmonary disease) lungs [1]. In addition to lung infections, $P A$ is also prevalent in contactlens-associated keratitis and is a major cause of burn infections $[2,3]$. The prevalence of $P A$ in many infections can be attributed to its ability to express a wide array of virulence factors and form biofilms [4] as well as its intrinsically high levels of resistance to many antibiotics [5].

Among the virulence factors expressed by $P A$ is the unipolarly localized surface appendage, type IV pilus (Tfp) [4]. Tfp deficiency attenuates the ability of $P A$ to

Dr. Gee W. Lau

Department of Pathobiology, University of Illinois at Urbana-Champaign 2001 South Lincoln Ave

Urbana, IL 61802 (USA)

E-Mail geelau@illinois.edu 
induce epithelial cytotoxicity, pneumonia, septicemia and mortality in mice $[6,7]$. Tfp is important for twitching motility, epithelial adhesion, substratum attachment and biofilm formation as well as phage attachment and uptake $[4,8]$. Tfp is made up of monomers of pilin, encoded by the pilA gene $[8,9]$. The assembly and disassembly of Tfp are powered by the ATPases PilB and PilT/U, respectively, producing twitching motility $[8,10]$. These extension and retraction proteins are regulated by the Chp chemosensory system [10]. The asialoGM1 [4, 8, 9, $11]$ and $\mathrm{N}$-glycan chains $[12,13]$ located on the apical surface of the host epithelium are the main receptors for Tfp.

The surfactant of the lung contains phospholipids and four major surfactant proteins (SPs): SP-A, B, C and D $[14,15]$. The naturally occurring octadecameric SP-A is the most abundant $[14,15]$. Each monomer contains an $\mathrm{N}$-terminal, triple-helical collagen region that binds to eukaryotic receptor (SP-A receptor 210), and a C-terminal carbohydrate-recognition domain (CRD) that binds to microbial carbohydrates [14-16]. Binding of the CRD to microbial carbohydrates aggregates microbes, enhancing their phagocytosis [14, 17-21]. In addition to opsonic phagocytosis, SP-A enhances phagocytosis directly [15, 22]. SP-A $\mathrm{A}^{-/-}$mice are more susceptible to lung infection, with decreased bacterial clearance and reduced macrophage phagocytosis $[15,23,24]$. Most recently, we and others have shown that SP-A directly permeabilizes microbial membranes [17-21].

Previously, our laboratory has shown that several virulence factors of $P A$, including lipopolysaccharide (LPS), phosphoenolpyruvate transferase, isochorismate synthase, flagellum and elastase B confer resistance to SP-Amediated antimicrobial effects [18-21]. In this paper, we show that Tfp of $P A$ also plays a major role in resistance to SP-A-mediated phagocytosis and membrane permeabilization.

\section{Materials and Methods}

Bacterial Strains and Growth Conditions

The wild-type $P A$ strain PAO1 and its isogenic derivatives $\triangle p i l A$, the genetically-complemented strain $\Delta p i l A$-comp, $\Delta \operatorname{ch} p A$, $\Delta p i l G, \Delta p i l B, \Delta p i l H, \Delta p i l T$ and $\Delta p i l U$ were generously provided by Prof. Joanne Engel (University of California, San Francisco, Calif., USA) [10]. The rpoN::ISphoA/hah mutant was purchased from the University of Washington Genome Sciences [25] (table 1). PA strains were grown in Luria-Bertani (LB) broth and stored at $-80^{\circ} \mathrm{C}$ in $30 \%$ glycerol. Before each experiment, bacteria were streaked from frozen stock onto LB agar for $18 \mathrm{~h}$ at $37^{\circ} \mathrm{C}$. One colony from this streak was then cultured in $5 \mathrm{ml} \mathrm{LB}$ broth to the stationary phase $\left(\mathrm{OD}_{600}\right.$ approx. 3.0).
Mouse Clearance Assay

Wild-type $\mathrm{C} 3 \mathrm{H} / \mathrm{HeN}\left(\mathrm{SP}_{-} \mathrm{A}^{+/+}\right)$mice were purchased from Harlan Laboratory (South Easton, Mass., USA). Isogenic SP-A ${ }^{-1-}$ mice were gifts from Dr. Francis McCormack (University of Cincinnati College of Medicine, Cincinnati, Ohio, USA). Mouse experiments complied with the guidelines and were approved by the University of Illinois at Urbana-Champaign Institutional Animal Care and Use Committee. SP-A $\mathrm{A}^{+/+}$and SP-A $\mathrm{A}^{-/-}$mice $(\mathrm{n}=5)$ were given a single intranasal inoculation of $1 \times 10^{7} \mathrm{PAO} 1$ or $\triangle p i l A$ strain. After $18 \mathrm{~h}$ of infection, mouse lungs were harvested for histology or bacterial enumeration as we previously described [18-21].

\section{In vivo Phagocytosis Assay}

The phagocytosis rates between different $P A$ strains were compared using the gentamicin exclusion assay as previously described [21]. Briefly, SP-A ${ }^{+/+}$and SP-A ${ }^{-/-}$mice $(\mathrm{n}=3)$ were given a single intranasal inoculation of $1 \times 10^{7} \mathrm{PAO} 1$ or $\Delta$ pilA cells. After $2 \mathrm{~h}$, mouse lungs were lavaged to collect the alveolar macrophages and neutrophils. The macrophages were then incubated in PBS supplemented with $100 \mu \mathrm{g} / \mathrm{ml}$ gentamicin to kill the remaining extracellular bacteria. The macrophages were lysed with $1 \%$ Triton X-100 solution and serially diluted for the enumeration of internalized $P A$. The ratio of CFU counts between SP- $\mathrm{A}^{+/+}$and SP- $\mathrm{A}^{-/-}$mice was computed for the fold increase of phagocytosis mediated by SP-A.

\section{Purification of Human SP-A}

Discarded lung washings from anonymous alveolar proteinosis patients were generously provided by Dr. Francis McCormack. Human (h)SP-A was purified as previously described [26]. Briefly, raw lung washings, equilibrated with $1 \mathrm{mM} \mathrm{CaCl}_{2}$, were passed through a Sepharose ${ }^{\circledR} 6 \mathrm{~B}$ column laden with mannose. The captured SP-A was eluted using the elution buffer ( 2 mM EDTA and $5 \mathrm{~mm}$ Tris- $\mathrm{HCl}, \mathrm{pH}$ 7.4). The eluted fractions were dialyzed using the dialysis buffer ( $150 \mathrm{mM} \mathrm{NaCl}$ and $5 \mathrm{mM}$ Tris- $\mathrm{HCl}, \mathrm{pH}$ 7.4) to remove EDTA. The purity of hSP-A preparations was confirmed by Coomassie blue stain.

Murine Macrophage Cell Line and in vitro Phagocytosis Assay Murine RAW 264.7 macrophages (ATCC\# TIB-71) were maintained in DMEM supplemented with $10 \%$ FBS at $5 \% \mathrm{CO}_{2}$ and $37^{\circ} \mathrm{C}$ [21]. The phagocytosis rates between different $P A$ strains were compared using the gentamicin exclusion assay. Briefly, $1 \times$ $10^{6} \mathrm{RAW} 264.7$ macrophages $/ \mathrm{ml}$ were plated in 6-well cell culture plates overnight in a $37^{\circ} \mathrm{C}$ incubator with $5 \% \mathrm{CO}_{2} . P A$ strains were preincubated with $12.5,25$ or $50 \mu \mathrm{g} / \mathrm{ml} \mathrm{hSP}$-A in the presence of $2 \mathrm{mM} \mathrm{CaCl}_{2}$ for 1,6 or $12 \mathrm{~h}$ in a shaker $(300 \mathrm{rpm})$ at $37^{\circ} \mathrm{C}$. The resulting mixture was then incubated with the RAW 264.7 cells at a ratio of bacteria/macrophages of $10: 1$ for $1.5 \mathrm{~h}$. The macrophages were then washed and incubated in fresh DMEM supplemented with $100 \mu \mathrm{g} / \mathrm{ml}$ gentamicin to kill the remaining extracellular bacteria. The macrophages were lysed with $1 \%$ Triton X-100 solution, and serially diluted for enumeration. The ratio of CFU between treated and untreated bacteria was computed for the fold increase of phagocytosis mediated by hSP-A.

\section{Aggregation Assay}

$P A$ strains were transformed with the plasmid pUCP19 harboring a green fluorescent protein (GFP) gene by electroporation as previously described [21]. Bacterial aggregation was performed using the stationary-phase $P A$ incubated with $25 \mu \mathrm{g} / \mathrm{ml} \mathrm{hSP-A}$ and 
Table 1. Bacterial strains and plasmids used in this study

\begin{tabular}{|c|c|c|}
\hline Strain or plasmid & Description & Reference \\
\hline \multicolumn{3}{|l|}{$P$. aeruginosa strains } \\
\hline PAÖ1 & wild-type & {$[10]$} \\
\hline$\Delta$ pilA-comp & genetically-complemented $\Delta$ pilA mutant & {$[10]$} \\
\hline PAO1-GFP & PAO1 harboring pUCP19-gfp & this study \\
\hline$\Delta p i l A-G F P$ & $\Delta p i l A$ harboring pUCP19-gfp & this study \\
\hline$\Delta p i l G$ & in-frame deletion of the pilG gene & {$[10]$} \\
\hline$\Delta p i l B$ & in-frame deletion of the pilB gene & {$[10]$} \\
\hline$\Delta$ pilH & in-frame deletion of the pilH gene & {$[10]$} \\
\hline$\Delta p i l T^{\mathrm{CTX}-\text { pilU }}$ & in-frame deletion of the pilT; pilU and $1 \mathrm{~kb}$ upstream sequence at attB site & {$[10]$} \\
\hline$\Delta$ pilu & in-frame deletion of the pilU gene & {$[10]$} \\
\hline rpoN::ISphoA/hah & mutant harboring a ISphoA/hah transposon insertion into the $r p o N$ gene & $\begin{array}{l}\text { University of Washington } \\
\text { Genome Sciences }\end{array}$ \\
\hline
\end{tabular}

$2 \mathrm{mM} \mathrm{CaCl}_{2}$ for $1 \mathrm{~h}$ in a shaker $(300 \mathrm{rpm})$ at $37^{\circ} \mathrm{C}$. Bacterial clusters were enumerated from 10 independent fields under a fluorescence microscope.

\section{Membrane Permeabilization Assay}

The membrane permeability effects of hSP-A were measured using both the thiol-specific fluorophore ThioGlo ${ }^{\circledR}$ (Calbiochem, San Diego, Calif., USA) and enzyme-labeled fluorescence phosphatase substrate ELF-97 ${ }^{\circledR}$ (Molecular Probes, Carlsbad, Calif., USA), as previously described $[17,20,21]$. Stationary-phase $P A$ bacteria were washed and incubated with either $50 \mu \mathrm{g} / \mathrm{ml} \mathrm{hSP}$-A for $15 \mathrm{~min}$ at $37^{\circ} \mathrm{C}$ or with $50 \mu \mathrm{g} / \mathrm{ml}$ total protein of bronchoalveolar lavage fluids (BALF) from either SP-A $\mathrm{A}^{+/+}$or SP-A $\mathrm{A}^{-/-}$mice. For the ThioGlo assay, the bacteria/SP-A mixture was sedimented, and the supernatant was incubated with $10 \mu \mathrm{M}$ ThioGlo. Fluorescence was measured at an excitation wavelength of $405 \mathrm{~nm}$ and an emission wavelength of $535 \mathrm{~nm}$. For the ELF-97 assay, the bacteria/SP-A mixture was directly incubated with $100 \mu \mathrm{M}$ ELF-97. Fluorescence was measured at an excitation wavelength of $355 \mathrm{~nm}$ and an emission wavelength of $535 \mathrm{~nm}$ every $3 \mathrm{~min}$ for a period of 90-120 min.

\section{Bacterial Viability Assay}

Stationary-phase $P A$ bacteria were washed and incubated with either $50 \mu \mathrm{g} / \mathrm{ml} \mathrm{hSP}-\mathrm{A}$ or $50 \mu \mathrm{g} / \mathrm{ml}$ total protein of BALF from either SP-A $\mathrm{A}^{+/+}$or SP-A ${ }^{-/-}$mice for $60 \mathrm{~min}$ or $6 \mathrm{~h}$ at $37^{\circ} \mathrm{C}$. The bacteria were then stained with a combination of $\mathrm{SYTO}^{\circledR} 9$ and propidium iodide from the commercial bacterial viability kit, LIVE/ DEAD ${ }^{\circledR}$ BacLight (Molecular Probes). The numbers of dead and live bacteria were counted in 10 independent high-power fields $(\times 400)$ using a fluorescent microscope.

\section{Elastase Assay}

Elastase production in the culture supernatant of stationaryphase $P A$ was evaluated using the Sensolyte ${ }^{\mathrm{TM}}$ Red Protease assay kit (AnaSpec Inc., San Jose, Calif., USA). Fluorescence was measured at excitation $546 \mathrm{~nm}$ and emission $575 \mathrm{~nm}$.

Type IV Pilus Mediates Resistance to SP-A

\section{Pyocyanin Assay}

Pyocyanin in the bacteria-free supernatant of stationary-phase $P A$ cultured in LB broth or a low-phosphate medium (20 mM succinic acid, $40 \mathrm{mM} \mathrm{NH}_{4} \mathrm{Cl}, 2 \mathrm{mM} \mathrm{K}_{2} \mathrm{SO}_{4}, 0.014 \mathrm{~g} \mathrm{NAH}_{2} \mathrm{PO}_{4}, 1 \mathrm{M}$ MOPS, $40 \mathrm{mM} \mathrm{MgCl}$, $100 \mathrm{mM} \mathrm{CaSO}_{4}, 100 \mathrm{mM} \mathrm{ZnCl}_{2}, 30 \mathrm{mM}$ $\mathrm{MnCl}_{2}$ and $30 \mathrm{mM} \mathrm{Fe}\left(\mathrm{NO}_{3}\right)$ were measured at $\mathrm{OD}_{690}$ [20].

\section{SDS Lysis Assay}

To assess the membrane stability of $P A$ strains, bacterial cell lysis was performed with $0.25 \%$ SDS as previously described [19]. Stationary-phase $P A$ bacteria $\left(\mathrm{OD}_{600} 3.0\right)$ were washed and resuspended in PBS with $0.25 \%$ SDS. The $\mathrm{OD}_{600}$ was measured every 10 $\min$ for $1 \mathrm{~h}$.

\section{LPS Analysis}

LPS was purified from stationary-phase $P A$ strains as follows: the bacteria were sedimented and resuspended in $200 \mu \mathrm{l}$ lysis buffer (2 g SDS, $4 \mathrm{ml}$ 2-mercaptoethanol, $0.003 \mathrm{~g}$ bromophenol blue and $1 \mathrm{M}$ Tris-Hcl, $\mathrm{pH}$ 6.8) and boiled for $10 \mathrm{~min}$. Three microliters of $20 \mu \mathrm{g} / \mu \mathrm{l}$ proteinase $\mathrm{K}$ were added, and the mixture was incubated for $1 \mathrm{~h}$ at $60^{\circ} \mathrm{C}$. The resulting mixture was separated in an SDS-PAGE gel. The resolved gel was incubated with a fixing solution $(25 \% \mathrm{v} / \mathrm{v}$ isopropyl alcohol and $7 \%$ $\mathrm{v} / \mathrm{v}$ acetic acid) overnight at $4{ }^{\circ} \mathrm{C}$, oxidized $(0.7 \%$ periodic acid, $2.7 \%$ ethanol and $0.3 \% \mathrm{v} / \mathrm{v}$ acetic acid) for $5 \mathrm{~min}$ with gentle agitation, and washed with water 3 times for $30 \mathrm{~min}$ each. The gel was then placed in staining solution ( $4 \% \mathrm{v} / \mathrm{v} 1 \mathrm{M} \mathrm{NaOH}, 5 \%$ $\mathrm{v} / \mathrm{v} \mathrm{NH}_{4} \mathrm{OH}$ and $2 \% \mathrm{AgNO}_{3}$ ) and shaken for $10 \mathrm{~min}$, followed by four washes in water for $10 \mathrm{~min}$ each. Finally, the gel was developed $(0.02 \%$ citric acid and $0.05 \% \mathrm{v} / \mathrm{v}$ formaldehyde) for 20 $\mathrm{min}$. The development was stopped using a stop solution $(0.8 \%$ $\mathrm{v} / \mathrm{v}$ acetic acid).

\section{Transmission Electron Microscopy}

$P A$ strains were grown to $\mathrm{OD}_{600}$ approximately 3.0 in LB broth at $37^{\circ} \mathrm{C}$. Bacteria were washed with PBS, and subsequently fixed 
Fig. 1. $\Delta$ pilA bacteria are more susceptible to clearance by SP-A. a Respiratory tract infections with wild-type PAO1 versus $\triangle$ pilA were performed by intranasal inoculation of anesthetized SP-A ${ }^{+/+}$or SP-A $\mathrm{A}^{-/-}$ mice. Mouse lungs were harvested $18 \mathrm{~h}$ after infection for bacterial enumeration. Data are the mean CFU \pm SE $(n=5$ per group). ${ }^{*} \mathrm{p}<0.05$ when comparing the bacterial loads between SP-A $\mathrm{A}^{+/+}$and SP-A ${ }^{-/-}$ infected by PAO1 or $\triangle$ pilA. ${ }^{*} \mathrm{p}<0.05$ when comparing the bacterial loads between PAO1 and $\triangle p i l A$ infecting the SP-A ${ }^{+/+}$or $\mathrm{SP}_{-} \mathrm{A}^{-/-}$mice. $\mathbf{b}$ The growth kinetics of $\mathrm{PAO} 1$ and $\triangle p i l A$ bacteria were determined by measuring $\mathrm{OD}_{600}$. The experiments were performed independently in triplicate. The representative growth curve from 1 of 3 independent experiments is shown.

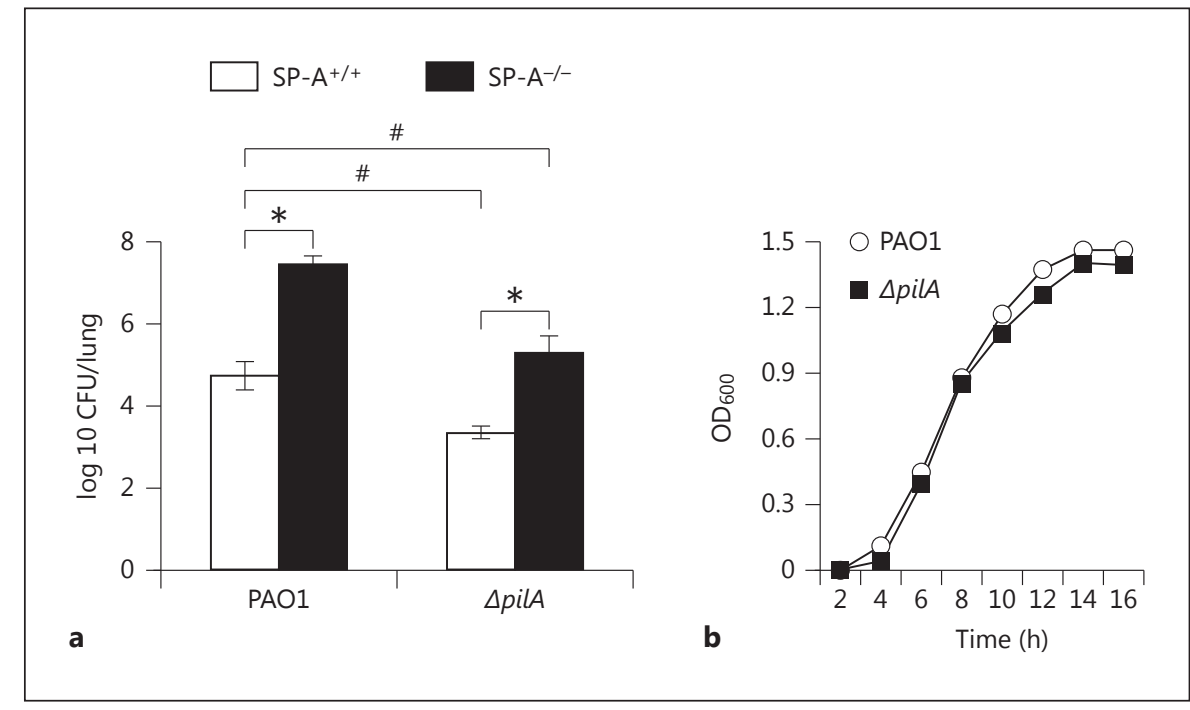

using the Karnovsky fixative. Transmission electron microscopy (TEM) was performed at the University of Illinois Material Research Laboratory.

\section{Ligand Blot}

Biotinylated SP-A was used to identify potential receptors in $P A$ strains as previously described [16]. Briefly, stationary-phase bacteria were ruptured under 14,000 psi in a French press. Membranes were isolated in $100 \mathrm{~mm}$ sodium carbonate and centrifuged at $115,000 \mathrm{~g}$. Isolated membranes were solubilized using $50 \mathrm{~mm}$ Tris $\mathrm{pH} 7.4$ mixed with loading buffer, boiled for $5 \mathrm{~min}$ and then resolved using 15\% SDS-PAGE gels. Gels were either stained using Coomassie blue or transferred to PVDF membranes. Membranes were blocked for $2 \mathrm{~h}$, and subsequently incubated with $3 \mu \mathrm{g} / \mathrm{ml}$ biotinylated SP-A. After 3 washings, streptavidin-conjugated HRP was added. Signal was detected using commercially available Western blot stain and substrate. Ligand blot signal was analyzed with the Image J software. Corresponding bands in gels stained with Coomassie blue to the signal detected in the PVDF membrane were sent for analyses at the University of Illinois LC-MS/MS core facility.

\section{Results}

Tfp Is Important in Resistance to SP-A-Mediated Lung Clearance

To determine the contribution of Tfp-mediated resistance to SP-A, we compared the virulence of the wild-type $P A P A O 1$ and the isogenic $\triangle$ pilA mutant in a mouse model of acute pneumonia. Eighteen hours after intranasal inoculation with $\mathrm{PAO} 1$ or $\Delta p i l A, \mathrm{SP}-\mathrm{A}^{+/+}$mice showed signs of infection and respiratory distress but were not moribund. In contrast, $\mathrm{PAO} 1$-infected SP-A ${ }^{-/-}$mice were moribund and had to be euthanized (data not shown). The number of viable PAO1 or $\Delta$ pilA bacteria in $\mathrm{SP}-\mathrm{A}^{-/-}$ were $2.74 \log$ and $1.97 \log$ higher than in $\mathrm{SP}-\mathrm{A}^{+/+}$mice, respectively (fig. 1a). The number of $\Delta$ pilA bacteria in SP$\mathrm{A}^{-1-}$ mice was statistically indistinguishable when compared to the number of PAO1 in the SP-A $\mathrm{A}^{+/+}$mice, suggesting that $\triangle p i l A$ was more virulent during lung infection in the absence of SP-A. However, the viable counts of $\triangle$ pilA were $1.4 \mathrm{log}$ lower than PAO1 in $\mathrm{SP}_{-} \mathrm{A}^{+/+}$mice and 2.16 log lower than PAO1 in $\mathrm{SP}_{-} \mathrm{A}^{-/-}$mice. Because the relative decrease of bacterial load between $\mathrm{PAO} 1$ and $\triangle$ pilA from SP-A ${ }^{-/-}$mice to SP-A ${ }^{+/+}$mice was only 0.77 $\log$, this suggests that $\Delta p i l A$ is in general less virulent. In addition, other innate immune factors of the lung within the alveolar space may compensate for the absence of SPA. Thus, a straightforward link between Tfp and SP-A cannot be easily established (fig. 1a). The $\Delta$ pilA showed similar growth kinetics to that of PAO1, suggesting that the difference in mouse clearance was not due to the growth defects in the former (fig. 1b).

The aforementioned quantitative observations were supported by histopathology (fig. 2). In the absence of bacterial infection, histopathological features of SP-A $\mathrm{A}^{-1-}$ mouse lungs were indistinguishable when compared to the lungs of SP-A ${ }^{+/+}$mice [data not shown]. PAO1 caused moderate bronchopneumonia (fig. 2a) whereas the $\Delta$ pilA mutant only caused mild bronchopneumonia in the lungs of SP-A $\mathrm{A}^{+/+}$mice (fig. 2b). In contrast, PAO1 caused severe bronchopneumonia in SP-A ${ }^{-/-}$mice, with large amounts of pulmonary infiltrates and consolidation (fig. 2c). Importantly, $\Delta$ pilA caused more severe pulmonary infiltrate in SP-A $\mathrm{A}^{-/-}$mice (fig. $2 \mathrm{~d}$ ) than the SP-A $\mathrm{A}^{+/+}$mice (fig. $2 \mathrm{~b}$ ). The severity of $\Delta p i l A$-mediated bronchopneumonia in SP-A ${ }^{-/}$lungs (fig. $2 \mathrm{~d}$ ) was similar to that caused by PAO1 


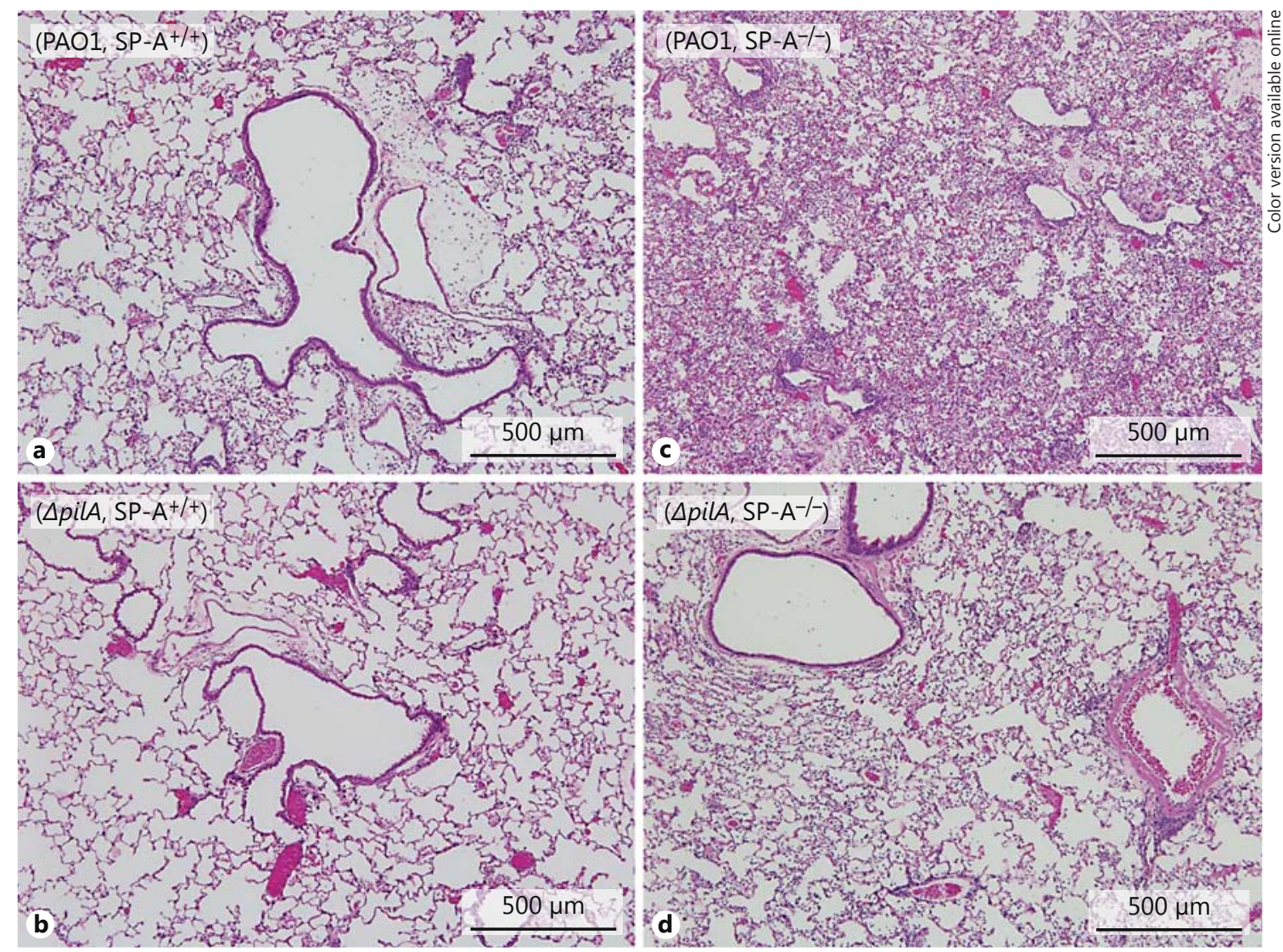

Fig. 2. Histopathology of $P A$-infected lungs. SP-A $\mathrm{A}^{+/+}$and $\mathrm{SP}-\mathrm{A}^{-/-}$mice were infected with $\mathrm{PAO} 1$ or $\triangle p i l A$ as described in figure 1 . Representative HE-stained lung sections from SP-A ${ }^{+/+}$and SP-A ${ }^{-/-}$mice $(\mathrm{n}=5) 18 \mathrm{~h}$ after intranasal instillation of PAO1 $(\mathbf{a}, \mathbf{c})$ and $\Delta p i l A$ (b, d) bacteria.

Fig. 3. The $\triangle p i l A$ mutant is more susceptible to SP-A-mediated opsonization. ac RAW 264.7 macrophages were infected with either PAO1 or $\triangle$ pilA in the presence or absence of hSP-A. The ratio of ingested bacteria was expressed as fold increase in phagocytosed bacteria due to the effect of hSP-A. a Phagocytosis of PAO1, $\Delta p i l A$ and genetically complemented $\triangle p i l A$-comp in the presence of $25 \mu \mathrm{g} / \mathrm{ml} \mathrm{hSP-A.} \mathrm{b} \mathrm{Phago-}$ cytosis of PAO1 and $\triangle p i l A$ in the presence of different concentrations of hSP-A. c Time-dependent phagocytosis of PAO1 versus $\triangle$ pilA in the presence of $25 \mu \mathrm{g} / \mathrm{ml}$ hSP-A. d In vivo phagocytosis of PAO1 versus $\Delta$ pilA in $\mathrm{SP}-\mathrm{A}^{+/+}$and $\mathrm{SP}-\mathrm{A}^{-/-}$mice $(\mathrm{n}=3)$. All phagocytosis experiments were independently performed in triplicate. The mean \pm standard deviation from 1 representative experiment is shown. ${ }^{*} \mathrm{p}<0.05$ when comparing the number of phagocytosed $\Delta$ pilA to PAO1.

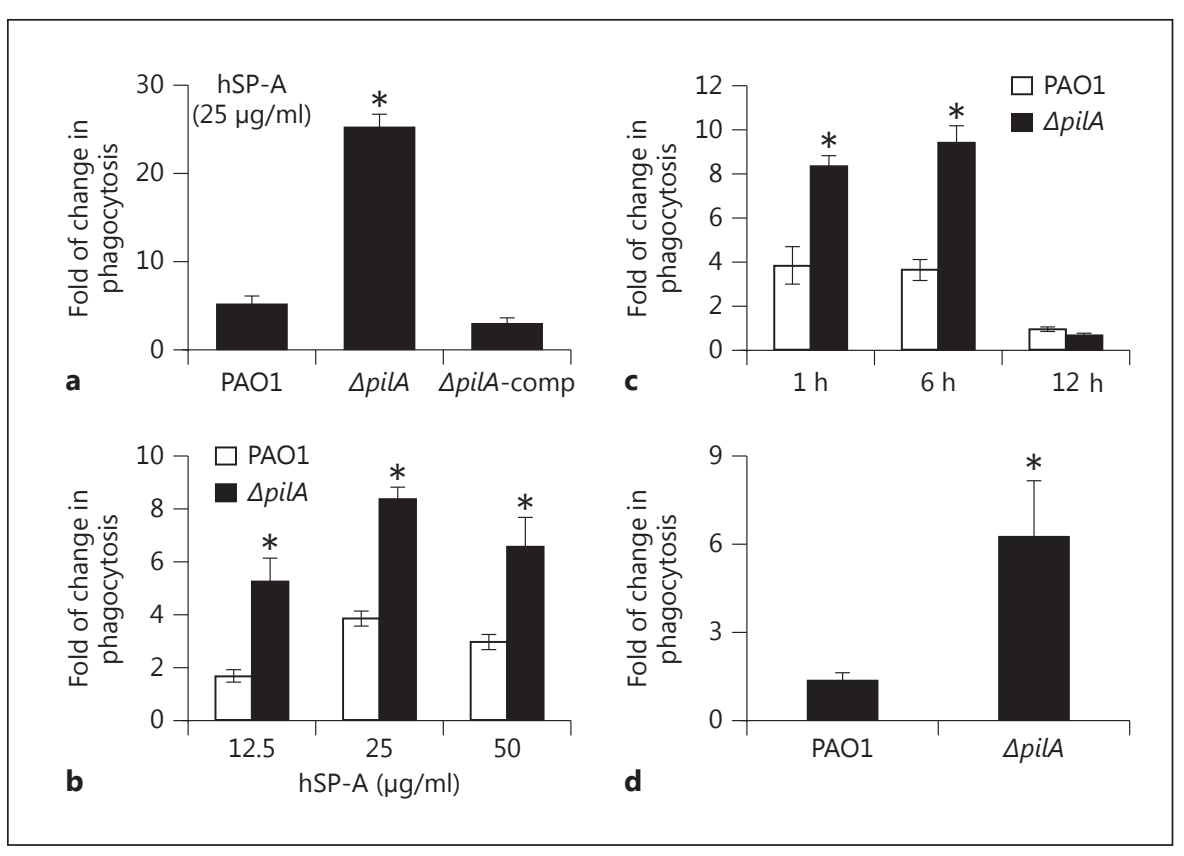

Type IV Pilus Mediates Resistance to SP-A
J Innate Immun 2014;6:227-239 DOI: $10.1159 / 000354304$ 

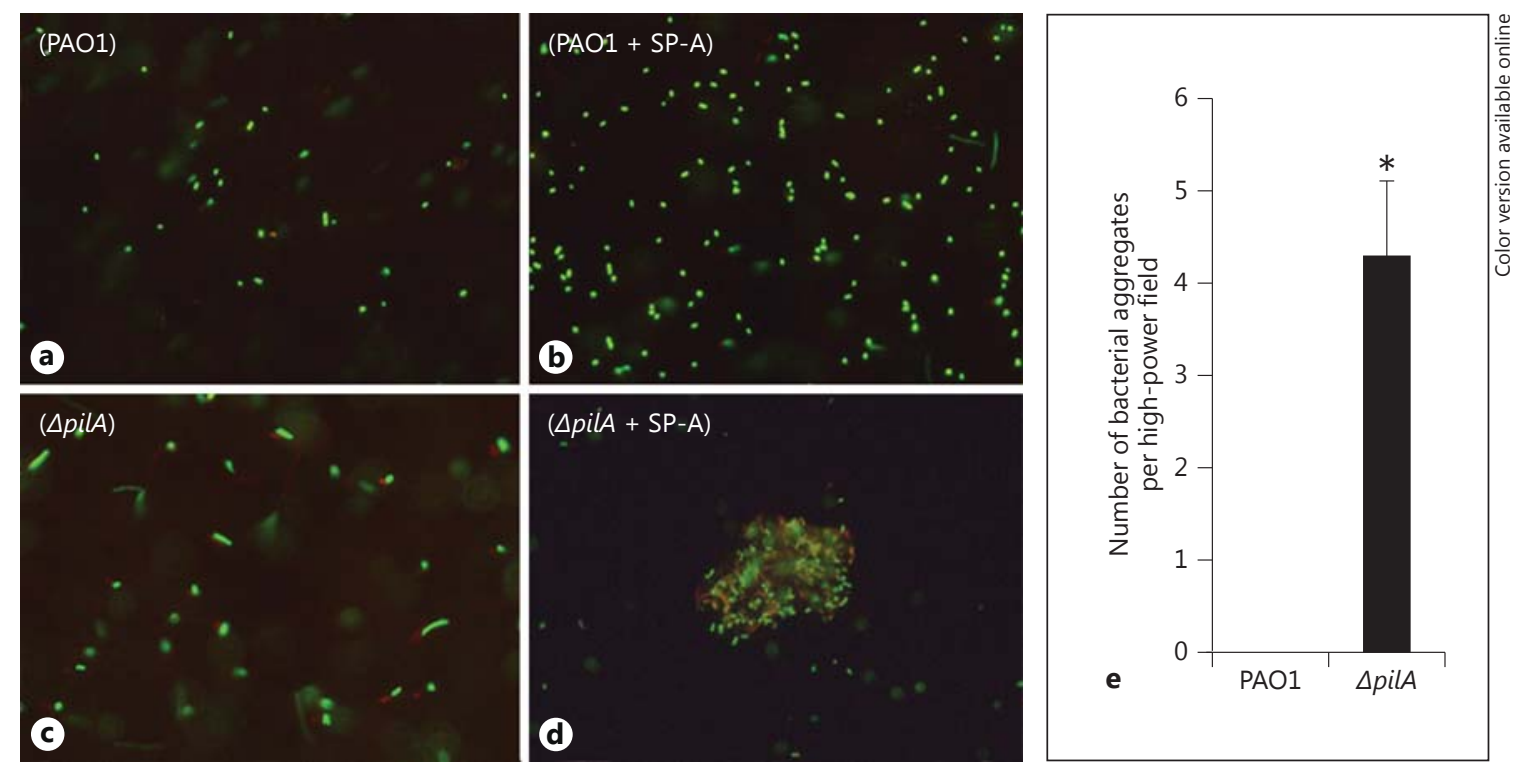

Fig. 4. $\triangle p i l A$ are more susceptible to SP-A-mediated aggregation. GFP-expressing PAO1 and $\triangle$ pilA bacteria were incubated with 25 $\mu \mathrm{g} / \mathrm{ml} \mathrm{hSP}-\mathrm{A}$ for $1 \mathrm{~h}$ and examined under a confocal fluorescence microscope. a PAO1 without hSP-A. b PAO1 with hSP-A. c $\Delta p i l A$

without hSP-A. d $\triangle p i l A$ with hSP-A. e The number of aggregates was averaged from 10 independent high-power fields. ${ }^{*} \mathrm{p}<0.05$ when comparing the number aggregates in $\triangle p i l A$ to PAO1.

in $\mathrm{SP}_{-} \mathrm{A}^{+/+}$lungs (fig. $2 \mathrm{a}$ ), suggesting that the virulence levels of $\triangle$ pilA in mouse lungs devoid of SP-A was similar to PAO1 in mouse lungs with sufficient SP-A. Collectively, these results indicate that Tfp plays a protective role against anti- $P A$ activity mediated by SP-A.

\section{Tfp Is Important for Resistance of SP-A-Mediated Phagocytosis}

To decipher the mechanism of Tfp resistance in SP-Amediated lung clearance, we examined whether $\Delta p i l A$ bacteria were more susceptible to SP-A-mediated opsonization. In the presence of $25 \mu \mathrm{g} / \mathrm{ml}$ of SP-A, $\Delta p i l A$ bacteria were phagocytized 5 times more efficiently than the wild-type PAO1 (fig. 3a). The genetically-complemented $\triangle$ pilA-comp bacteria were as resistant to SP-Amediated opsonization as PAO1 (fig. 3a). These results were confirmed by studies using different concentrations of SP-A, which consistently showed that, in the presence of SP-A, $\Delta$ pilA was more susceptible to phagocytosis by macrophages than PAO1 (fig. 3b). We also examined the phagocytosis of $\triangle$ pilA in a time-dependent manner. Again, $\triangle p i l A$ was more susceptible to SP-A-mediated opsonization at 1 and $6 \mathrm{~h}$ after exposure to RAW $264.7 \mathrm{mac}-$ rophages (fig. 3c). However, prolonged exposure (12 h) abolished phagocytosis, most probably because both PAO1 and $\triangle$ pilA bacteria degraded SP-A by secreting

exoproteases, as we have previously described [20,21]. These observations were confirmed by an in vivo phagocytosis assay, which showed that $\triangle$ pilA was 4.5 times more susceptible to SP-A-mediated opsonization than PAO1 (fig. 3d). The in vivo phagocytosis assay measures the total phagocytosis activity involving both alveolar macrophages and infiltrating neutrophils responding to $P A$ infection. Collectively, these results indicate that Tfp is important for resistance to SP-A-mediated opsonization.

\section{Tfp Is Important for Resistance to SP-A-Mediated Aggregation}

One of the mechanisms by which SP-A enhances microbial phagocytosis is by increasing their aggregation, allowing more efficient phagocytosis [22]. We compared the aggregation of wild-type PAO1 versus $\Delta$ pilA by SP-A in vitro. The $\triangle p i l A$ mutant bacteria were aggregated by SP-A 4-fold higher than PAO1 per high-power field (fig. 4a-e). Overall, these results show that Tfp confers resistance to SP-A-mediated aggregation.

\section{Tfp Is Important for Resistance to SP-A-Mediated}

Membrane Permeabilization

Apart from its ability to opsonize and facilitate the phagocytosis of microbes by macrophages, SP-A is also 


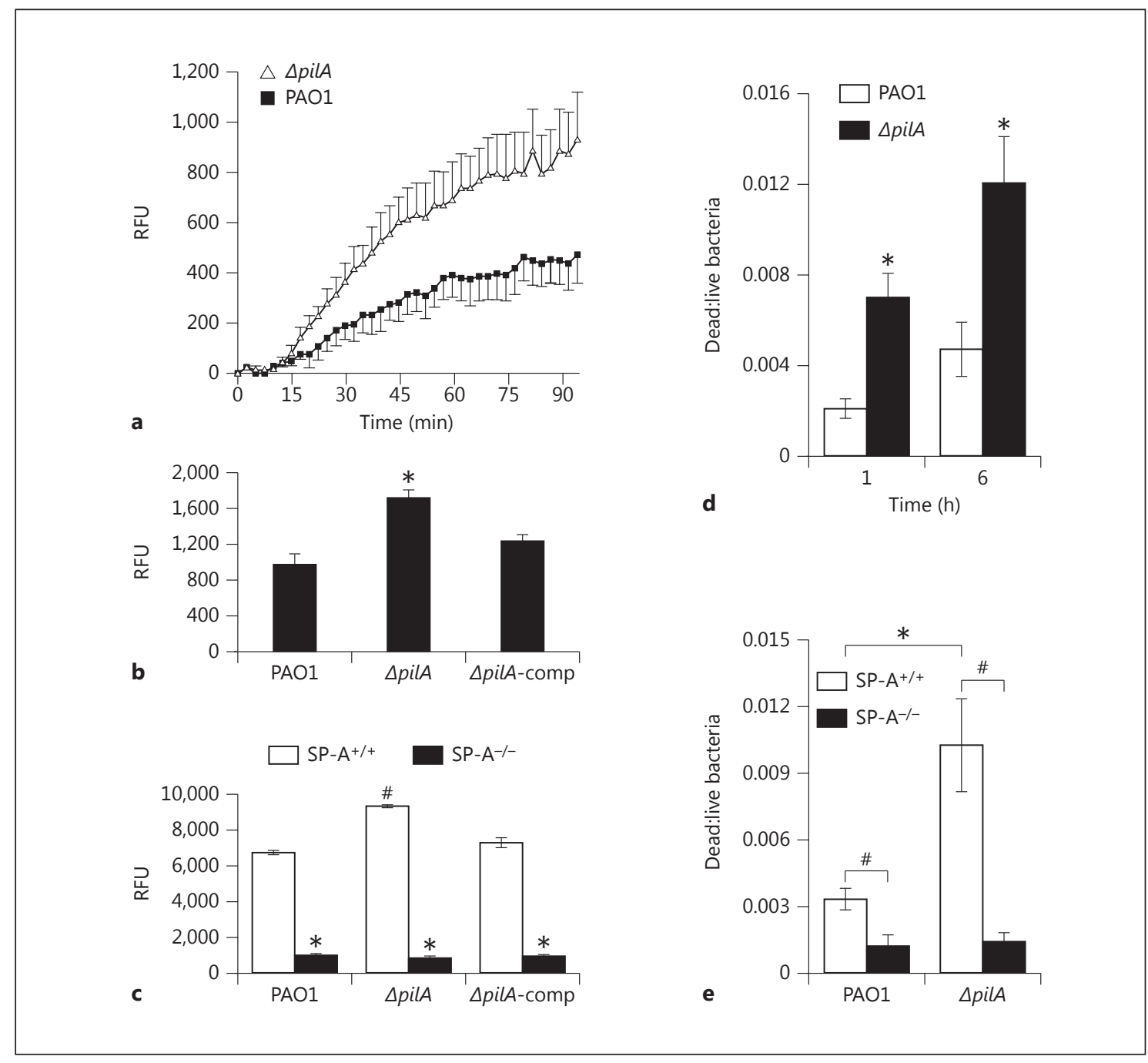

Fig. 5. $\triangle$ pilA are more susceptible to SP-A-mediated membrane permeabilization. a ELF-97 assay. PAO1 and $\Delta$ pilA were preincubated with $50 \mu \mathrm{g} / \mathrm{ml} \mathrm{hSP-A} \mathrm{for} 15 \mathrm{~min}$ before the addition of ELF97. Absorbance was measured every $3 \mathrm{~min}$ at excitation wavelength $355 \mathrm{~nm}$ and emission wavelength $535 \mathrm{~nm}$, for a total of 90 min. b In vitro ThioGlo assay. PAO1, $\Delta p i l A$ and $\Delta p i l A$-comp were preincubated with $50 \mu \mathrm{g} / \mathrm{ml} \mathrm{hSP}$-A for $15 \mathrm{~min}$. The bacteria-free supernatants were then mixed with ThioGlo. Absorbance was measured at excitation wavelength $405 \mathrm{~nm}$ and emission wavelength $535 \mathrm{~nm} . * \mathrm{p}<0.05$ when comparing the relative fluorescence unit (RFU) of $\triangle p i l A$ to PAO1 and $\Delta p i l A$-comp. (c) Ex vivo ThioGlo assay. PAO1, $\triangle p i l A$ and $\triangle p i l A$-comp were preincubated with $50 \mu \mathrm{g} / \mathrm{ml}$ total protein of BALF from either SP-A ${ }^{+/+}$mice or SP$\mathrm{A}^{-/-}$mice for $1 \mathrm{~h}$. The bacteria-free supernatants were then mixed with ThioGlo. Absorbance was measured at excitation wavelength $405 \mathrm{~nm}$ and emission wavelength $535 \mathrm{~nm}$. ${ }^{*} \mathrm{p}<0.05$ when comparing the RFU of $\triangle p i l A$ to PAO1 and $\triangle p i l A$ in BALF from SP-A $\mathrm{A}^{+/+}$ mice. ${ }^{*} \mathrm{p}<0.05$ when comparing the RFU of each $P A$ strain in BALF from SP-A ${ }^{+/+}$to $\mathrm{SP}-\mathrm{A}^{-/-}$mice. $\mathbf{d}$ In vitro $P A$ killing by $\mathrm{hSP}$ A. PAO1 and $\triangle p i l A$ were preincubated with $50 \mu \mathrm{g} / \mathrm{ml} \mathrm{hSP-A}$ for 1 or $6 \mathrm{~h}$. The bacteria were then stained with a mixture of SYTO 9 and propidium iodide for $15 \mathrm{~min}$. The ratio of dead-to-live bacteria is counted in 10 high-power fields. ${ }^{*} \mathrm{p}<0.05$ when comparing the ratio of dead-to-live $\triangle$ pilA to PAO1 bacteria in the presence of hSP-A. e Ex vivo $P A$ killing by mouse SP-A within BALF. PAO1 and $\triangle p i l A$ were preincubated with $50 \mu \mathrm{g} / \mathrm{ml}$ total protein of BALF from either SP-A $\mathrm{A}^{+/+}$mice or SP-A $\mathrm{A}^{-/-}$mice for $1 \mathrm{~h}$. Bacterial viability was determined as in $\mathbf{d} .{ }^{\#} \mathrm{p}<0.05$ when comparing the ratio of dead-to-live bacteria between those treated with BALF from SP$\mathrm{A}^{+/+}$and SP-A ${ }^{-/-}$mice. ${ }^{*} \mathrm{p}<0.05$ when comparing the ratio of dead-to-live PAO1 to $\triangle$ pilA-treated with BALF from $\mathrm{SP}-\mathrm{A}^{+/+}$ mice. Experiments were performed independently in triplicate (for ELF-97 and ThioGlo assays) or duplicate (for the LIVE/DEAD assay). Data from 1 typical experiment are shown. 
Fig. 6. The susceptibility of Tfp extension and retraction mutants to SP-A-mediated opsonization. a, b RAW 264.7 macrophages were infected with PAO1, $\Delta$ pilA and the extension or retraction mutants in the presence or absence of hSP-A. The ratio of ingested bacteria between those exposed to hSP-A to those unexposed was expressed as fold increase in phagocytosis. a Phagocytosis of PAO1, $\triangle$ pilA and extension mutants $\Delta$ chpA, $\Delta p i l G$ and $\Delta p i l B$. b Phagocytosis of PAO1, $\triangle p i l A$ and retraction mutants $\Delta$ pilH, $\Delta$ pilT and $\Delta$ pilU. ${ }^{*} \mathrm{p}<0.05$ when comparing phagocytosis of PAO1 to the $\Delta$ pilA mutant. ${ }^{\#} \mathrm{p}<0.05$ when comparing phagocytosis of PAO1 to the $\Delta$ pilT and $\Delta p i l U$ mutants. All experiments were independently performed in triplicate. The mean \pm standard deviation from 1 representative experiment is shown. c, d Membrane permeabilization of $P A$ strains by hSP-A. c Membrane permeabilization of PAO1, $\triangle p i l A$ and extension mutants $\triangle \operatorname{ch} p A, \Delta p i l G$ and $\triangle p i l B$. d Membrane permeability of PAO1, $\triangle p i l A$ and retraction mutants $\Delta p i l H, \Delta p i l T$ and $\Delta p i l U$. All experiments were independently performed in triplicate. The mean \pm standard deviation from 1 representative experiment is shown.

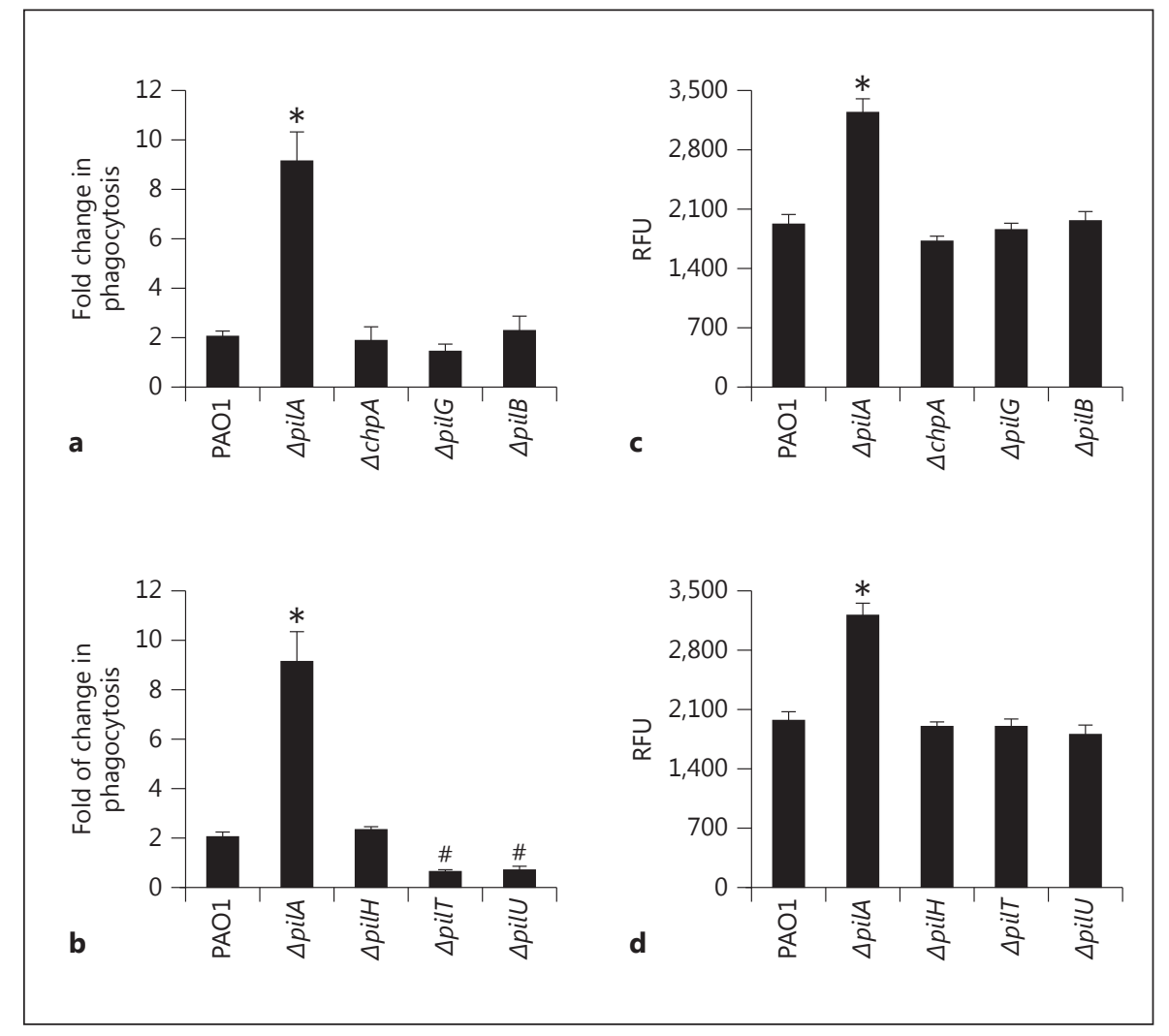

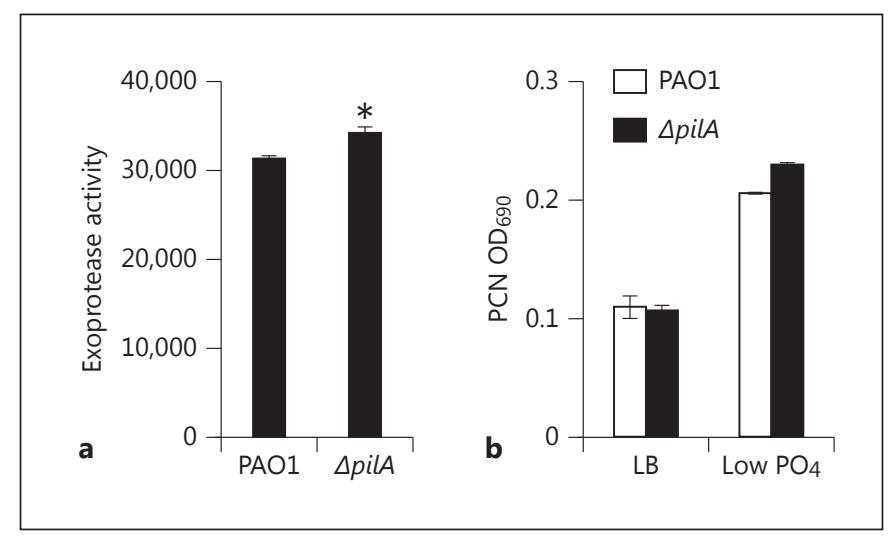

Fig. 7. Resistance to SP-A-mediated phagocytosis is independent of quorum sensing. a Exoprotease activity of PAO1 versus $\triangle p i l A$. b Pyocyanin production of PAO1 versus $\Delta$ pilA.

capable of directly killing bacteria by membrane permeabilization [17-19]. We examined the susceptibility of $\Delta$ pilA to SP-A-mediated membrane permeabilization, by measuring the diffusion of an impermeable phosphatase substrate ELF-97 into PA cells, and by measuring the leakage of thiol-containing proteins. After $90 \mathrm{~min}$ of exposure, the ELF-97 assay indicated that $\Delta$ pilA bacteria were permeabilized 2.1-fold higher than the PAO1 (fig. 5a). In addition, the leakage of thiol-containing proteins increased by 1.81 -fold relative to PAO1 (fig. 5b). To confirm our in vitro observations, we compared the ability of BALF of SP-A $\mathrm{A}^{+/+}$and SP-A ${ }^{-/-}$mice to permeabilize the membrane of PAO1 and $\Delta$ pilA (fig. 5c). The $\Delta p i l A$ bacteria were more susceptible to BALF from SP-A ${ }^{+/+}$ mice than PAO1. In contrast, BALF from SP-A ${ }^{-/-}$only possessed low levels of membrane-permeabilizing capability, suggesting that SP-A is an important membranepermeabilizing protein within the BALF. To determine whether increased susceptibility to membrane permeability leads to direct bacterial killing, we examined the bacterial viability after exposure to hSP-A and to BALF. Although both the hSP-A and the BALF from SP-A ${ }^{+/+}$ mice only caused low levels of $P A$ killing, the $\triangle p i l A$ was consistently shown to be significantly more susceptible to direct killing by hSP-A (fig. 5d) and BALF of SP-A $\mathrm{A}^{+/+}$ mice (fig. 5e). These results suggest that SP-A-mediated membrane permeabilization contributes minimally to $P A$ clearance. 
Fig. 8. Resistance to SP-A-mediated phagocytosis is regulated by RpoN. a Comparison of bacterial phagocytosis by RAW 264.7 macrophages between PAO1, $\Delta$ pilA and $r p o N:: I S p h o A / h a h$ in the presence or absence of $25 \mu \mathrm{g} / \mathrm{ml}$ hSP-A. All experiments were independently performed in triplicate. The mean \pm standard deviation from 1 representative experiment is shown. $* \mathrm{p}<0.05$ when comparing PAO1 to $\Delta p i l A$. \# $\mathrm{p}<0.05$ when comparing PAO1 to rpoN::ISphoA/hah. b Ligand blot analysis of nonpilus adhesins in PAO1, $\Delta$ pilA and rpoN::ISphoA/hah. c Image J analysis of the ligand blot. Protein expression was normalized to PAO1 as $100 \%$. d Protein sequence of OprH. e Comparison of membrane permeabilization between PAO1, $\triangle p i l A$ and $r p o N:: I S p h o A / h a h$. The experiments were independently performed in triplicate. The mean \pm standard deviation from 1 representative experiment is shown. $* \mathrm{p}<0.05$ when comparing PAO1 to $\Delta p i l A$ and rpoN::ISphoA/hah.

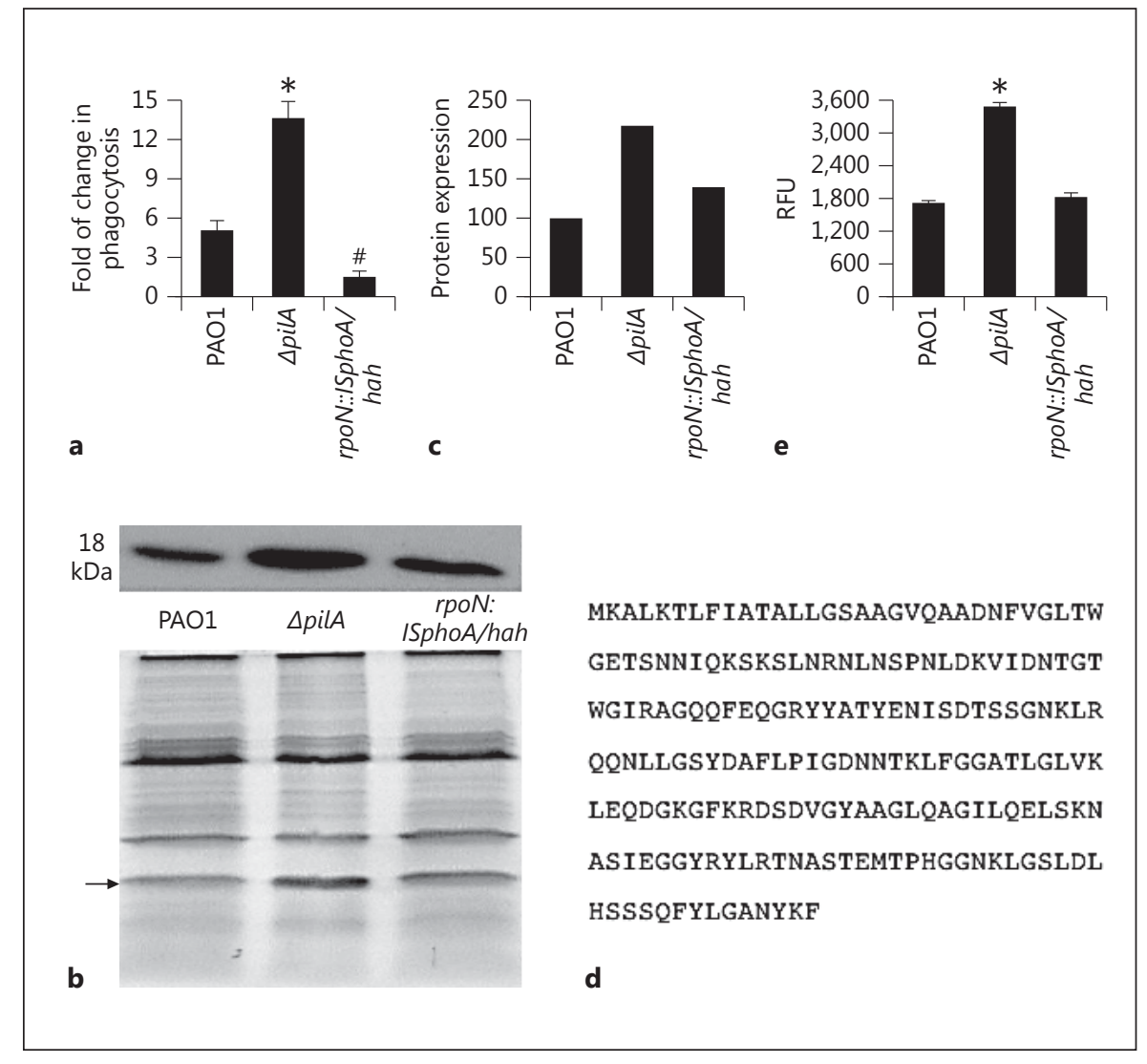

Tfp-Mediated Resistance to SP-A-Mediated

Phagocytosis Is Independent of the Presence of the

Appendages on the Cell Surface

Compared to other $P A$ mutants we have studied previously $[15,16,27,28], \triangle p i l A$ is uniquely more susceptible to both SP-A-mediated opsonization and membrane permeabilization. We used both the pilin extension $(\Delta c h p A$, $\Delta p i l G$ and $\Delta p i l B)$ and retraction $(\Delta p i l H, \Delta p i l T$ and $\Delta p i l U)$ mutants to determine if the presence of Tfp on the cell surface of $P A$ is required for resistance to both SP-A-mediated opsonization and membrane permeabilization. As shown in figure $6 \mathrm{a}$, the mere absence of Tfp on the bacterial surface in the extension mutants $(\Delta c h p A, \Delta p i l G$ and $\triangle p i l B)$ does not increase susceptibility to SP-A-mediated phagocytosis. Interestingly, the retraction mutants, $\Delta p i l T$ and $\Delta$ pilU, which are hyperpiliated, are more resistant to SP-A-mediated opsonization (fig. 6b). Both extension and retraction mutants were as resistant to SP-A-mediated membrane permeabilization as PAO1 (fig. 6c, d). Collectively, these results suggest that the presence of pilin anchoring the membranes is adequate to confer resistance to SP-A-mediated phagocytosis. In addition, ex-

Type IV Pilus Mediates Resistance to SP-A pression of additional Tfp (e.g. $\Delta p i l T$ and $\Delta p i l U$ mutants) offers increased resistance to SP-A-mediated phagocytosis.

Increased Susceptibility of $\triangle$ pilA to SP-A-Mediated

Phagocytosis Is Probably Due to a Compensatory

Increase in Nonpilus Adhesins

Previous work in our laboratory has shown that $P A$ confers resistance to SP-A-mediated phagocytosis by increasing the degradation of SP-A through elastase B [20, 21 ], through mechanisms regulated by both flagellum and quorum-sensing. Flagellar-deficient mutants are deficient in quorum sensing, decreasing their ability to produce adequate elastase B to degrade SP-A. However, $\Delta$ pilA produced wild-type levels of both quorum-sensingregulated exoprotease activities (fig. 7a) and the redoxactive secondary metabolite pyocyanin (fig. 7b). Furthermore, the $\triangle$ pilA lost its susceptibility to SP-A-mediated phagocytosis after $12 \mathrm{~h}$ (fig. 3c), suggesting that SP-A was degraded. Thus, the lack of quorum-sensing and SP-A degradation is not the cause of enhanced opsonization of $\Delta$ pilA by SP-A. 
Fig. 9. $\triangle$ pilA is more susceptible to SDSmediated cell lysis. a LPS analysis of PAO1 and $\triangle p i l A$ as visualized using silver stain. $\mathbf{b}$, c TEM of PAO1 and $\triangle$ pilA, respectively. Bar $=100 \mathrm{~nm}$. d SDS lysis assay. PAO1 and $\triangle$ pilA bacteria were incubated in $0.25 \%$ SDS solution. $\mathrm{OD}_{600}$ was measured every $10 \mathrm{~min}$. Bacterial lysis experiments were independently performed in triplicate. The mean from 1 representative experiment is shown.
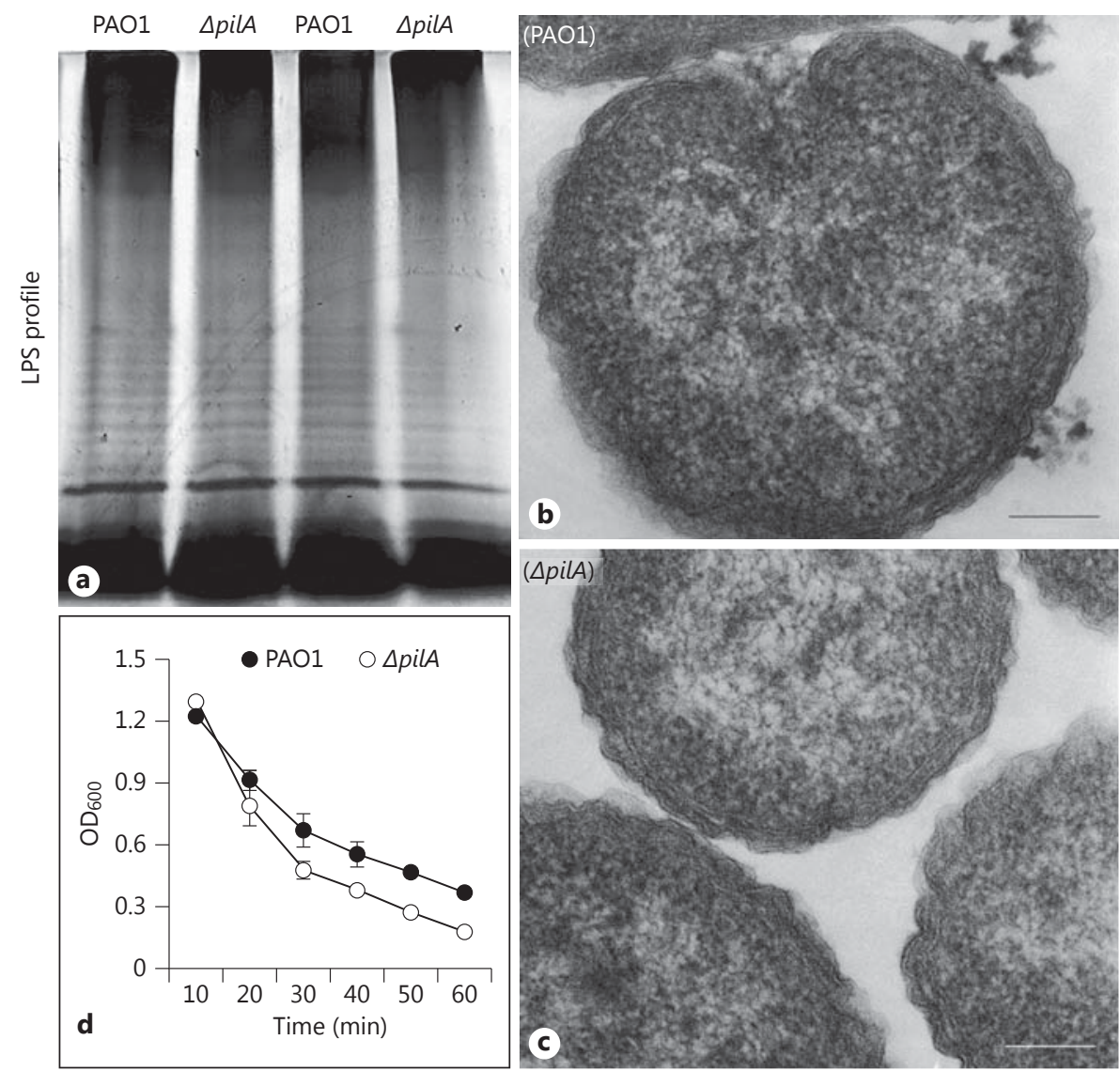

Previous studies have shown that $\Delta p i l A$ has a higher binding affinity to host epithelial cells than the hyperpiliated mutants $\Delta$ pilT and $\Delta p i l U$ [29-32]. This is speculated to be caused by overexpression of alternative 'nonpilus adhesins' in $\triangle$ pilA. The alternative sigma factor RpoN has been shown to regulate the expression of these adhesins [29-32]. We hypothesized that one or more of these nonpilus adhesins may serve as ligands for binding to SP-A. We compared the phagocytosis of $\Delta p i l A$ versus rpoN::ISphoA/hah in the presence of SP-A. Figure 8a shows $r p o N:: I S p h o A / h a h$, which lacks the adhesins, is more resistant to SP-A-mediated phagocytosis than both wild-type $\mathrm{PAO} 1$ and $\triangle p i l A$. Importantly, ligand blot analysis shows that the $\triangle$ pilA overexpresses a protein of approximately $18 \mathrm{kDa}$ compared to both $\mathrm{PAO} 1$ and rpoN::ISphoA/hah (fig. 8b, c). LCMS/MS and microsequencing analyses indicate that this putative adhesin is the outer membrane protein $\mathrm{H} 1$ precursor $\mathrm{OprH}$ (PA1178) (fig. 8d). Finally, rpoN::ISphoA/hah does not exhibit increased susceptibility to SP-A-mediated membrane permeabilization, suggesting that these nonpilus adhesins are dispensable against the pore-forming function of SP-A (fig. 8e).

$\triangle$ pilA Has Reduced Membrane Stability, Rendering It Susceptible to SP-A-Mediated Membrane

\section{Permeabilization}

Next, we examined the potential mechanisms of increased susceptibility of $\Delta$ pilA to SP-A-mediated membrane permeabilization. Previously, we have shown that the loss of LPS $[18,19]$ and flagellum [19-21] destabilizes membrane integrity, rendering them more susceptible to SP-A-mediated membrane permeabilization. In addition, Abeyrathne et al. [33] have shown that the O-antigen ligase mutant, $\Delta$ waaL, which is unable to attach $\mathrm{O}$ antigen to the core polysaccharide of LPS, has absent or decreased Tfp and flagella. We examined whether the absence of Tfp destabilizes the membranes, through reduced expression of LPS. Qualitative analyses of both the LPS and the TEM images of bacterial membranes show no discernible differences between $\triangle p i l A$ and PAO1 (fig. 9a-c). However, $\triangle$ pilA was more slightly more sus- 
ceptible to lysis by $0.25 \%$ SDS, suggesting that the loss of pilin modestly compromises the integrity of the outer membranes in the mutant bacteria (fig. $9 \mathrm{~d}$ ).

\section{Discussion}

SP-A is a major pulmonary innate immunity protein that mediates microbial clearance through opsonization and membrane permeabilization. However, little is known about the mechanisms elaborated by microbial pathogens to confer resistance or susceptibility to SP-A. Previously, we have demonstrated that several $P A$ factors: LPS, flagellum, isochorismate synthase and phosphoenolpyruvate phosphotransferase confer resistance to SP-A-mediated membrane permeabilization [18-21]. Flagellum also regulates the quorum-sensing-mediated expression of elastase B that degrades and disables SPA-mediated opsonization during phagocytosis [19-21]. In this study, we found that Tfp of $P A$ is uniquely important for resistance to SP-A-mediated opsonization and membrane permeabilization. Several lines of evidence support this argument: (1) $\triangle p i l A$ is preferentially cleared in the lungs of SP-A $\mathrm{A}^{+/+}$mice compared to SP-A $\mathrm{A}^{-/-}$mice, (2) $\triangle$ pilA is more susceptible to SP-A-mediated aggregation and opsonization, (3) $\triangle p i l A$ is more susceptible to SP-A-mediated membrane permeabilization and (4) the genetically complemented $\triangle p i l A$-(comp strain, which carries a copy of the wild-type pilA gene in trans, has restored resistance to SP-A-mediated opsonization and membrane permeabilization.

At face value, our report seems to contradict previous findings, which show that Tfp-deficient $P A$ strains, including $\triangle p i l A$, are more resistant to phagocytosis by macrophages [34-36]. However, this discrepancy can be explained because of different experimental context. Firstly, these previously published studies were pertaining to nonopsonin-mediated, fibronectin-dependent phagocytosis. Secondly, the number of phagocytized bacteria was quantified using a semi-quantitative fluorescent technique, rather than the quantitative method we used with the gentamicin exclusion assay. However, the gentamicin exclusion assay, which has been used for decades to quantify microbial phagocytosis, has its disadvantages. Because phagocytes ingest both individual and SP-A-aggregated bacteria, we cannot rule out the possibility that the vigorous pipetting and vortexing procedures used during serial dilution plating may not completely disaggregate bacteria. However, even if this were the case, $\Delta p i l A$, which is more susceptible than PAO1 to SP-A-mediated aggre-

Type IV Pilus Mediates Resistance to SP-A gation, would be undercounted. This would mean that the actual difference in phagocytic factor between $\triangle p i l A$ and PAO1 would be even higher, further supporting our results showing that $\triangle p i l A$ is more susceptible to SP-Amediated opsonization and phagocytosis.

A careful examination of data presented in figure 3 (a, b) indicates that there is variation in the efficiency of phagocytosis in different sets of experiments. This is not unusual, due to the fact that bacteria and macrophage cultures are not 'identical' from one set of experiments to the next; for example, the number of bacterial cells used in each experiment certainly differs slightly. Another contributing factor to the variation in phagocytic efficiency is that different batches of SP-A preparations derived by lung washing from different alveolar proteinosis patients may have different antimicrobial activity and potency. Nevertheless, in each experiment described, $\Delta p i l A$ is consistently more susceptible to SP-A-mediated opsonization and membrane permeabilization.

Detailed genetic analyses of the $P A$ mutants defective in retraction and extension of Tfp reveal rather unexpected mechanisms by which the pilus mediates resistance to SP-A-mediated phagocytosis. For example, the extension gene mutants $(\Delta c h p A, \Delta p i l G$ and $\Delta p i l H)$ did not show increased susceptibility to SP-A-mediated phagocytosis. These results suggest that a total absence of pilA both intracellularly and extracellularly is required to render $P A$ becoming susceptible to SP-A-mediated opsonization. We postulate that the absence of pilA causes a compensatory increase of alternative ligands that actually interact with SP-A. This is supported by previous studies showing that Tfp-deficient $P A$ mutants (e.g. $\triangle p i l A$ ) have higher adhesion to epithelial cells than hyperpiliated Tfp extension mutants strains $\Delta p i l T$ and $\Delta p i l U$, suggesting that Tfp-independent adhesins are responsible for increased binding to epithelial cells $[7,29]$. Importantly, both hyperpiliated Tfp mutants $\Delta p i l T$ and $\Delta p i l U$ are significantly more resistant than the wild-type PAO1 to SP-A-mediated phagocytosis. These observations suggest that additional Tfp expressed by both $\Delta$ pilT and $\Delta p i l U$ mutants may have masked the putative ligands, decreasing SP-Amediated binding, aggregation and subsequent opsonization, and enhanced phagocytosis by phagocytes.

Previous work has shown that the alternative sigma factor, RpoN, positively regulates both pilin and flagellin production through their respective 2-component systems PilRS and FleQR $[32,37]$. Thus, RpoN deficiency results in the loss of both Tfp and flagellum in $P A$. Interestingly, $\triangle p i l A$ has been used as a model to study the expression of alternative nonpilus adhesins. In contrast, 
rpoN mutation has been used as a model for the lack of nonpilus adhesins [30-32]. We speculate that the absence of Tfp causes RpoN to magnify the production of nonpilus adhesins, which serve as ligands for SP-A. This argument is supported by our analyses showing that $\Delta r p o N$ is even more resistant to SP-A-mediated phagocytosis than PAO1. Several studies have tried to determine the identity of these nonpilus adhesins, with most of them focusing on those that bind mucins $[27,28,38,39]$. Other studies focus on the role of nonpilus adhesins in nonopsonic phagocytosis [30, 31, 39]. However, the identity of these adhesins remains elusive. Another complication is the uncertainty whether the alternative adhesins associated with binding to mucin are the same as those conferring susceptibility to SP-A-mediated phagocytosis. By using ligand blot, we have identified a putative non-pilus adhesin that binds SP-A. LC-MS/MS and micro-sequencing analyses show that the SP-A ligand is the $18-\mathrm{kDa}$ outer membrane protein $\mathrm{H} 1$ precursor OprH. OprH expression is governed by low-magnesium environment through the PhoP-PhoQ two-component regulatory system $[40,41]$. Interestingly, $\mathrm{OprH}$ is noted to have direct interaction with LPS, which is bound by the CRD of SP-A [40]. Another outer membrane protein, P2 of Hemophilus influenzae, has been shown to be a receptor of SP-A [42]. We are currently constructing nonpolar deletion mutant and study the genetic, molecular and cellular interactions of OprH with Tfp, RpoN, and SP-A. Furthermore, we are examining the sequence and functional homology between OprH and H. influenzae P2.

Tfp interacts with glycoconjugates (e.g. asialoGM1) on the host epithelium [4]. Similarly, SP-A also interacts with glycoconjugates through its CRD. Thus, another possible mechanism of preferential clearance of $\Delta p i l A$ mutant from mouse lungs is that SP-A may have blocked Tfp receptors, and preventing the binding of $P A$ to the airway epithelium of wild-type mice. In contrast, in SP$\mathrm{A}^{-/-}$mice, these $\mathrm{Tfp}$ receptors will be exposed, allowing better binding and colonization of PA to the lungs devoid of SP-A. Future studies will include performing comparative in vivo binding of wild-type versus various Tfp mutants to the lung epithelium of $\mathrm{SP}-\mathrm{A}^{+/+}$versus $\mathrm{SP}-\mathrm{A}^{-/-}$ mice.

Our experimental evidence demonstrates that Tfp also mediates resistance to $\mathrm{SP}$-A-mediated membrane permeabilization. Following exposure to hSP-A and to the BALF from $\mathrm{SP}-\mathrm{A}^{+/+}$mice, the integrity of the outer membranes is compromised, rendering the $\triangle p i l A$ bacteria more permeable to the phosphatase substrate ELF-97 into the cells and increased leakage of thiol-containing intracellular proteins out of the cells. Previously, we have shown the the wild-type strain $\mathrm{PAO} 1$ is highly resistant to direct killing by SP-A. Although $\triangle$ pilA is more susceptible to SP-Amediated membrane permeabilization, this only results in small increase in direct killing of the bacteria, suggesting that the pore-forming process may be transient. Qualitative LPS analysis and TEM examination of membrane structures did not reveal any gross alterations in $\Delta p i l A$. However, $\triangle$ pilA bacteria have reduced membrane stability as demonstrated by a modest increase of cell lysis by $0.25 \%$ SDS.

In conclusion, we have shown that Tfp is important for resistance to SP-A-mediated opsonization and membrane permeabilization. We provide evidence that Tfp may camouflage nonpilus adhesin, and prevent the binding of SP-A to these ligands, reducing the opsonization and phagocytosis by macrophages. In addition, Tfp is necessary to stabilize bacterial membranes, rendering $P A$ more resistant to SP-A-mediated membrane permeabilization. Adjunctive treatment regimen aimed at inhibiting Tfp may help to improve the clearance of $P A$ by augmenting the efficiency of SP-A in killing this important respiratory pathogen.

\section{Acknowledgments}

We thank Ms. Jennifer Ida for her critical reading of the manuscript. We thank Profs Jeff Whitsett and Tom Korfhagen (Cincinnati Children's Hospital) for the gift of the Swiss Black SP-A ${ }^{-1-}$ mice and Professor Frank McCormack for the C3H SP-A ${ }^{-1-}$ mice and alveolar proteinosis lavage. We thank Professor Joanne Engel for providing $P A$ mutants. This work was supported in part by NIH grant HL090699 and an American Lung Association DeSouza Research Award to G.W.L. This investigation was conducted in a facility constructed with the support from Research Facilities Improvement Program Grant Number C06 RR 16515-01 from the National Center for Research Resources, National Institutes of Health.

References $\nabla_{1}$ Sadikot RT, Blackwell TS, Christman JW Prince AS: Pathogen-host interactions in Pseudomonas aeruginosa pneumonia. Am J Respir Crit Care Med 2005;171:1209-1223.

2 Willcox MD: Pseudomonas aeruginosa infection and inflammation during contact lens wear: a review. Optom Vis Sci 2007;84:273278.

3 Bielecki P, Glik J, Kawecki M, Martins dos Santos VA: Towards understanding Pseudomonas aeruginosa burn wound infections by profiling gene expression. Biotechnol Lett 2008;30:777-790. 
-4 Lau GW, Hassett DJ, Britigan BE: Modulation of lung epithelial functions by Pseudomonas aeruginosa. Trends Microbiol 2005;13:389-397.

-5 Breidenstein EB, de la Fuente-Nunez C, Hancock RE: Pseudomonas aeruginosa: all roads lead to resistance. Trends Microbiol 2011;19: 419-426.

-6 Tang H, Kays M, Prince A: Role of Pseudomonas aeruginosa pili in acute pulmonary infection. Infect Immun 1995;63:1278-1285.

7 Comolli JC, Hauser AR, Waite L, Whitchurch CB, Mattick JS, Engel JN: Pseudomonas aeruginosa gene products pilT and pilU are required for cytotoxicity in vitro and virulence in a mouse model of acute pneumonia. Infect Immun 1999;67:3625-3630.

$\checkmark 8$ Craig L, Pique ME, Tainer JA: Type IV pilus structure and bacterial pathogenicity. Nat Rev Microbiol 2004;2:363-378.

9 Hansen JK, Forest KT: Type IV pilin structures: insights on shared architecture, fiber assembly, receptor binding and type II secretion. J Mol Microbiol Biotechnol 2006;11: 192-207.

10 Bertrand JJ, West JT, Engel JN: Genetic analysis of the regulation of type IV pilus function by the Chp chemosensory system of Pseudomonas aeruginosa. J Bacteriol 2010;192:994-1010.

-11 Comolli JC, Waite LL, Mostov KE, Engel JN: 23 Pili binding to asialo-GM1 on epithelial cells can mediate cytotoxicity or bacterial internalization by Pseudomonas aeruginosa. Infect Immun 1999;67:3207-3214.

12 Bucior I, Mostov K, Engel JN: Pseudomonas aeruginosa-mediated damage requires distinct receptors at the apical and basolateral surfaces of the polarized epithelium. Infect Immun 2010;78:939-953.

13 Bucior I, Pielage JF, Engel JN: Pseudomonas aeruginosa pili and flagella mediate distinct binding and signaling events at the apical and basolateral surface of airway epithelium. PLoS Pathog 2012;8:e1002616.

14 Kishore U, Greenhough TJ, Waters P, Shrive AK, Ghai R, Kamran MF, Bernal AL, Reid KB, Madan T, Chakraborty T: Surfactant proteins SP-A and SP-D: structure, function and receptors. Mol Immunol 2006;43:12931315.

15 Kuroki Y, Takahashi M, Nishitani C: Pulmonary collectins in innate immunity of the lung. Cell Microbiol 2007;9:1871-1879.

-16 Sever-Chroneos Z, Krupa A, Davis J, Hasan $M$, Yang CH, Szeliga J, Herrmann M, Hussain M, Geisbrecht BV, Kobzik L, Chroneos ZC: Surfactant protein A (SP-A)-mediated clearance of Staphylococcus aureus involves binding of SP-A to the staphylococcal adhesin $\mathrm{EAP}$ and the macrophage receptors SP-A receptor 210 and scavenger receptor class A. J Biol Chem 2011;286:4854-4870.

17 Wu H, Kuzmenko A, Wan S, Schaffer L, Weiss A, Fisher JH, Kim KS, McCormack FX: Surfactant proteins A and D inhibit the growth of Gram-negative bacteria by increasing membrane permeability. J Clin Invest 2003;111:1589-1602.
18 Zhang S, Chen Y, Potvin E, Sanschagrin F, Levesque RC, McCormack FX, Lau GW: Comparative signature-tagged mutagenesis identifies Pseudomonas factors conferring resistance to the pulmonary collectin SP-A. PLoS Pathog 2005;1:259-268.

19 Zhang S, McCormack FX, Levesque RC, O’Toole GA, Lau GW: The flagellum of Pseudomonas aeruginosa is required for resistance to clearance by surfactant protein A. PLoS One 2007;2:e564.

20 Kuang Z, Hao Y, Hwang S, Zhang S, Kim E, Akinbi HT, Schurr MJ, Irvin RT, Hassett DJ, Lau GW: The Pseudomonas aeruginosa flagellum confers resistance to pulmonary surfactant protein-A by impacting the production of exoproteases through quorum-sensing. Mol Microbiol 2011;79:1220-1235.

-21 Kuang Z, Hao Y, Walling BE, Jeffries JL, Ohman DE, Lau GW: Pseudomonas aeruginosa elastase provides an escape from phagocytosis by degrading the pulmonary surfactant protein-A. PLoS One 2011;6:e27091.

-22 van Iwaarden F, Welmers B, Verhoef J, Haagsman HP, van Golde LM: Pulmonary surfactant protein A enhances the host-defense mechanism of rat alveolar macrophages. Am J Respir Cell Mol Biol 1990;2:91-98.

23 Crouch E, Wright JR: Surfactant proteins A and $\mathrm{D}$ and pulmonary host defense. Annu Rev Physiol 2001;63:521-554.

24 Giannoni E, Sawa T, Allen L, Wiener-Kronish J, Hawgood S: Surfactant proteins A and D enhance pulmonary clearance of Pseudomonas aeruginosa. Am J Respir Cell Mol Biol 2006;34:704-710.

25 Young RL, Malcolm KC, Kret JE, Caceres SM, Poch KR, Nichols DP, Taylor-Cousar JL, Saavedra MT, Randell SH, Vasil ML, Burns JL, Moskowitz SM, Nick JA: Neutrophil extracellular trap (net)-mediated killing of Pseudomonas aeruginosa: evidence of acquired resistance within the CF airway, independent of CFTR. PLoS One 2011;6:e23637.

26 Suwabe A, Mason RJ, Voelker DR: Calcium dependent association of surfactant protein $\mathrm{A}$ with pulmonary surfactant: application to simple surfactant protein A purification. Arch Biochem Biophys 1996;327:285-291.

27 Arora SK, Ritchings BW, Almira EC, Lory S, Ramphal R: Cloning and characterization of Pseudomonas aeruginosa FliF, necessary for flagellar assembly and bacterial adherence to mucin. Infect Immun 1996;64:21302136.

28 Reddy MS: Binding between Pseudomonas aeruginosa adhesins and human salivary, tracheobronchial and nasopharyngeal mucins. Biochem Mol Biol Int 1996;40:403-408.

29 Lorenz E, Chemotti DC, Vandal K, Tessier PA: Toll-like receptor 2 represses nonpilus adhesin-induced signaling in acute infections with the Pseudomonas aeruginosa pilA mutant. Infect Immun 2004;72:4561-4569.

30 Mork T, Hancock RE: Mechanisms of nonopsonic phagocytosis of Pseudomonas aeruginosa. Infect Immun 1993;61:3287-3293.
31 Mahenthiralingam E, Speert DP: Nonopsonic phagocytosis of Pseudomonas aeruginosa by macrophages and polymorphonuclear leukocytes requires the presence of the bacterial flagellum. Infect Immun 1995;63:4519-4523.

-32 Ramphal R, Koo L, Ishimoto KS, Totten PA, Lara JC, Lory S: Adhesion of Pseudomonas aeruginosa pilin-deficient mutants to mucin. Infect Immun 1991;59:1307-1311.

-33 Abeyrathne PD, Daniels C, Poon KK, Matewish MJ, Lam JS: Functional characterization of WaaL, a ligase associated with linking $\mathrm{O}$-antigen polysaccharide to the core of Pseudomonas aeruginosa lipopolysaccharide. J Bacteriol 2005; 187:3002-3012.

34 Lee DJ, Cox D, Li J, Greenberg S: Rac1 and $\mathrm{Cdc} 42$ are required for phagocytosis, but not NF-kappaB-dependent gene expression, in macrophages challenged with Pseudomonas aeruginosa. J Biol Chem 2000;275:141-146.

35 Kelly NM, Kluftinger JL, Pasloske BL, Paranchych W, Hancock RE: Pseudomonas aeruginosa pili as ligands for nonopsonic phagocytosis by fibronectin-stimulated macrophages. Infect Immun 1989;57:3841-3845.

36 Mahenthiralingam E, Campbell ME, Speert DP: Nonmotility and phagocytic resistance of Pseudomonas aeruginosa isolates from chronically colonized patients with cystic fibrosis. Infect Immun 1994;62:596-605.

-37 Potvin E, Sanschagrin F, Levesque RC: Sigma factors in Pseudomonas aeruginosa. FEMS Microbiol Rev 2008;32:38-55.

38 Plotkowski MC, Tournier JM, Puchelle E: Pseudomonas aeruginosa strains possess specific adhesins for laminin. Infect Immun 1996;64:600-605.

39 Carnoy C, Scharfman A, Van Brussel E, Lamblin G, Ramphal R, Roussel P: Pseudomonas aeruginosa outer membrane adhesins for human respiratory mucus glycoproteins. Infect Immun 1994;62:1896-1900.

40 Edrington TC, Kintz E, Goldberg JB, Tamm LK: Structural basis for the interaction of lipopolysaccharide with outer membrane protein $\mathrm{H}(\mathrm{OprH})$ from Pseudomonas aeruginosa. J Biol Chem 2011;286:39211-39223.

41 Macfarlane ELA, Kwasnicka A, Ochs MM, Hancock REW: PhoP \pm PhoQ homologues in Pseudomonas aeruginosa regulate expression of the outer-membrane protein OprH and polymyxin B resistance. Mol Microbiol 1999; 34:305-316.

42 McNeely TB, Coonrod JD: Aggregation and opsonization of Type A but not Type B Hemophilus influenzae by surfactant protein-A. Am J Respir Cell Mol Biol 1994;11:114-122.
Type IV Pilus Mediates Resistance to SP-A
J Innate Immun 2014;6:227-239 DOI: $10.1159 / 000354304$ 